\title{
Ser quilombola: representações sociais de habitantes de uma comunidade negra
}

\author{
Black community inhabitants' Social representations
}

\author{
Gilberto Lima dos SANTOS \\ Antonio Marcos CHAVES
}

\begin{abstract}
Resumo
Este estudo teve como objetivo conhecer as representações sociais de moradores de uma comunidade remanescente de quilombo, sobre a própria comunidade, no norte da Bahia. Participaram 20 membros da comunidade de Tijuaçu, de ambos os sexos, na faixa etária de 12 a 41 anos. Utilizou-se uma lista de complementação de frases, com onze frases incompletas, focalizando os seguintes temas: o lugar, os moradores, o suposto olhar dos outros, as mulheres, os homens, os mais velhos, os jovens, as crianças, ser quilombola, negritude, o futuro. As frases foram analisadas por tema, sendo agrupadas com base na similitude do sentido. Os resultados indicam que é através da tradição oral que se estabelece um compromisso histórico para com a resistência quilombola. E que os mais velhos são os difusores e mantenedores das representações mais antigas e estáveis, a partir das quais são ancorados os novos conhecimentos. Os resultados permitem a compreensão de que o quilombola enfrenta as condições adversas da vida assumindo uma dupla tarefa (individual e coletiva): garantir a sua sobrevivência (e de sua família) e fortalecer a comunidade na luta contra o preconceito e a discriminação. Além disso, os resultados ensejam novas possibilidades de pesquisa, sugerindo reflexões sobre a diversidade no âmbito da população negra.
\end{abstract}

Unitermos: comunidade quilombola; representações sociais; resistência.

\begin{abstract}
This study intended to acknowledge the social representations of black community inhabitants about their own community, located in the north of Bahia. Twenty members of Tijuaçu's black community took part in it, both men and women. The age range was from 12 to 41 years old. In order to do so, a Completing Phrases List was used, containing eleven incomplete phrases, focusing on the following themes: the place, the inhabitants, the supposed way others see it, the women, the men, the elders, theyoung, the children, being a black community inhabitant, the blackness, the future. The phrases were analyzed theme by theme, had being grouped according to the meaning similarity. The results indicated that through oral tradition, a historical commitment toward black community resistance has been established. They also indicated that the elder ones are responsible for spreading and maintaining the more ancient and stable representations, on which new knowledge is based. The results emerged the understanding that the black community inhabitant faces life adverse conditions assuming a double task (individual and collective): both assuring his own survival (concerning his family too) and strengthening black community fight against prejudice and discrimination. The results also suggested new research possibilities on researching and reflections about diversity within black population.

Uniterms: black community; social representations; resistance.

$\operatorname{rrv}$

1 Universidade Federal da Bahia, Faculdade de Filosofia e Ciências Humanas, Departamento de Psicologia, Curso de Mestrado em Psicologia. R. Antônio Balbino, 37, Maristas, 48970-000, Senhor do Bonfim, BA, Brasil. Correspondência para/Correspondence to: G.L. SANTOS. E-mail: <gilblimas@hotmail.com> Agradecimentos à Associação Agropastoril Quilombola de Tijuaçu e Adjacências, que viabilizou o acesso aos participantes.
\end{abstract}


A Lei Áurea (1888) pôs um ponto final no período escravocrata brasileiro e marcou, simultaneamente, o início de um longo processo de mudanças nos olhares dirigidos aos negros e às relações inter-raciais, tanto na dimensão do senso comum quanto nas produções científica e artística. O crescente reconhecimento da presença do preconceito étnico (e da subseqüente discriminação) na cultura brasileira não significou o seu desaparecimento, mas fez com que se tornasse cada vez mais sutil. E a manifestação sutil do preconceito não o fez menos insidioso. Ao contrário, conferiu-lhe certa invisibilidade (e imunidade) que the permite adentrar as instituições, apesar das leis construídas para barrá-lo.

Gouvêa (2005) analisou as representações sociais sobre o negro presentes na literatura infantil brasileira, nas três primeiras décadas do século XX. Ela observou que devido à inclusão do tema das relações raciais nas narrativas, havia naquele período uma interlocução entre a literatura infantil e os discursos científico e artístico. A autora verificou que nas duas primeiras décadas havia uma ausência de personagens negros; e considera que essa ausência correspondeu aos ideais de progresso e civilização predominantes na época, que seriam incompatíveis com a figura do negro, cujas práticas e história evocariam a ordem escravocrata como marca de um país atrasado.

A partir da década de 1920, com a emergência das discussões acerca da brasilidade, surge o negro nas narrativas. É um negro mitificado, ligado às raízes do país. Ao mesmo tempo em que é valorizado como identidade cultural constituinte da brasilidade, estereotipicamente é relegado ao primitivismo da tradição oral, que o põe num patamar cognitivo compatível com a ingenuidade infantil. A inserção do negro e da cultura africana nas narrativas ocorre a partir de um viés etnocêntrico do narrador branco, orientado por valores europeus. E isso de tal modo que as imagens estereotipadas do negro passam a ser preferencialmente a da"negra velha"e a do"preto velho"- remetidos ambos a um Brasil agrário -, imersos em práticas religiosas primitivas e crenças pré-científicas (Gouvêa, 2005).

Ainda segundo Gouvêa (2005), na década de 1930, estudos realizados sobre a identidade brasileira e sua composição racial resultaram em obras clássicas, a exemplo de Oliveira Vianna e Gilberto Freyre. Os estudos do primeiro desqualificavam o negro e defendiam o embranquecimento da população pela miscigenação. Os estudos do segundo consideravam a cultura negra positiva, mas mitificavam as relações raciais, concebendo-as como caracterizadoras de uma democracia racial.

Antes que se tornasse algo amplamente repudiado, muitas mudanças ocorreram no entendimento científico do preconceito racial. $\mathrm{Na}$ verdade, até o século XIX a concepção de preconceito não era científica e nem mesmo significativa. Segundo Duckitt (1992), naquele período a idéia da superioridade de brancos sobre negros era aceita tanto nos Estados Unidos quanto na Europa. As explicações eram principalmente evolucionárias, naturalizantes.

Foi durante a década de 1920 que a definição do "problema racial" começou a mudar radicalmente no âmbito da Psicologia. Essa mudança ocorreu de tal forma que, em 1940, os cientistas já buscavam a origem do "preconceito irracional". O problema social das relações raciais foi redefinido. A inferioridade dos negros foi substituída pelo preconceito dos brancos (Duckitt, 1992).

Para explicar o preconceito, nas décadas de 1930 e 1940 recorria-se à teoria psicodinâmica: o preconceito resultaria de processos psicológicos universais, a exemplo dos mecanismos de defesa. Atuando inconscientemente, esses processos canalizariam tensões e problemas emergentes (da personalidade ou de frustrações e ameaças ambientais) para preconceitos contra minorias (Duckitt, 1992).

Após a 2a Guerra Mundial, a ênfase passou dos processos à estrutura psicológica. O preconceito seria, então, a expressão de características estruturais da personalidade, de caráter psicológico. Assim, o preconceito passou a ser descrito em termos de diferenças individuais. Nessa direção, destacou-se mais a teoria da personalidade autoritária, que descrevia o grau em que indivíduos estariam propensos ao preconceito (Duckitt, 1992). Segundo Fiske (1998), a teoria da personalidade autoritária foi elaborada justamente a partir de pesquisas sobre o anti-semitismo. A síndrome descrita envolvia a submissão cega à autoridade, a adesão estrita às convenções da classe média, a tendência a pensar em categorias rígidas e a agressão a quem não fosse também assim convencional. 
Do final da década de 1950 à década de 1970, a ênfase foi deslocada do nível individual para as influências sociais e culturais. O preconceito era concebido como uma norma incorporada ao ambiente social, através de dois mecanismos: a socialização e a conformidade. Entre os anos 60 e os anos 70 emergiu a perspectiva de que o preconceito seria mantido por conflitos intergrupais e condições socioestruturais, que atenderiam aos interesses das elites. Na década de 1970, a despeito dos "surveys" mostrando que o preconceito racial havia diminuído nos Estados Unidos, surgiu a concepção do racismo simbólico, detectando que, em vez de declinar, o preconceito tornara-se mais sutil, complexo e insidioso (Duckitt, 1992). O racismo sutil surgiu no contexto de mudanças implementadas pelos avanços na legislação dos direitos civis. Expressar diretamente o racismo tornou-se uma alternativa socialmente indesejável (Fiske, 1998).

Nos anos 80 o preconceito passou a ser visto como uma expressão inevitável da categorização cognitiva, que determinaria fenômenos intergrupais como conflito, discriminação, estereotipização e preconceito (Duckitt, 1992). Como afirma Stangor (2000), estereótipos e preconceitos fazem parte do interesse central da psicologia social, que é compreender como as pessoas dão sentido e reagem umas às outras. Nossos estereótipos (crenças sobre as características de grupos) são compartilhados com outros indivíduos em nossa cultura. Ao categorizar uma pessoa, pensamentos (estereótipos) e sentimentos (preconceitos) dirigidos a ela são rapidamente ativados.

A indesejabilidade social da expressão direta do preconceito racial resultou de sua proibição legal em muitos países. Em função disso, as crenças na inferioridade dos negros, por exemplo, têm ganhado manifestações mais sutis por parte dos brancos. Uma alternativa pode ser a busca do favorecimento do endogrupo, ao invés da discriminação do exogrupo; ou, no lugar da atribuição de características negativas ao exogrupo, a não atribuição de características positivas (Camino, Silva \& Machado, 2004).

De acordo com Duckitt (1992), o estudo do preconceito tem sido um empreendimento predominantemente norte-americano, sobretudo como tentativa de compreender diferenças raciais. Mas, no Brasil, pesquisas importantes também têm sido desenvolvidas.
Segundo Camino et al. (2004), as pesquisas indicam que a maioria dos brasileiros reconhece que existe o preconceito racial no país, mas poucos assumem ser individualmente preconceituosos. Esses autores afirmam que estudos anteriores sugeriam-Ihes que "o preconceito é expresso mais facilmente quando o sujeito não se encontra numa situação claramente de relações inter-raciais" (p.125).

Nesse ponto convém assinalar que, apesar da ampla constatação de que o negro tem sido percebido secularmente pelo prisma do preconceito e da visão etnocêntrica, ainda são poucos os estudos que buscam compreender como o próprio negro se percebe, que imagens cria a respeito de si mesmo. Um exemplo é o estudo de Cavalleiro (2003), efetuado no município de São Paulo, sobre a presença das relações raciais no processo de socialização. Participaram do estudo três gerações sucessivas de famílias negras, de baixa renda. A autora obteve a reconstrução da história de vida das mulheres (avós e mães - 1a e $2^{a}$ gerações) e das crianças (3a geração).

Cavalleiro (2003) buscou saber especialmente como as mulheres têm pensado na socialização das crianças em relação ao pertencimento racial e às dificuldades resultantes do racismo, o preconceito e a discriminação; e também como as crianças pensam, sentem e expressam seu pertencimento racial nas relações sociais que estabelecem. A autora concluiu que as mulheres negras vivem a experiência do medo e não sabem como conduzir a educação dos seus filhos e netos quanto ao racismo presente na sociedade. Acabam submetendo-os a processos semelhantes aos que viveram, ou seja, silenciam quanto ao enfrentamento do racismo, deixando o problema por conta do esforço e resistência individuais e familiares.

Outro estudo nessa direção foi realizado por Paré (2000), que visou verificar a auto-estima e o sucesso ou fracasso escolar do aluno negro. Utilizando o método fenomenológico, a autora detectou um entrecruzamento da discriminação existente na escola, decorrente do preconceito racial, social, escolar e para com o deficiente físico, dos sentimentos gerados pela discriminação, da família e sua afetividade, das relações sociais como libertadoras ou inibidoras do processo de aprender, das percepções de si (em termos de potencialidade e de aprendizagem), da percepção do 
contexto escolar, dos mecanismos de defesa como reação à discriminação, dos projetos de vida e da "consciência negra".

Situando-se na perspectiva do interesse em contribuir para a compreensão da diversidade existente no âmbito da população negra, este estudo visa saber quais representações a respeito de si mesmos os membros de uma comunidade quilombola compartilham. Isto é, pretende-se conhecer as representações que os quilombolas expressam ao caracterizar sua vida comunitária, sua identidade social, seu sentimento de pertencimento e sua resistência às representações mais abrangentes sobre as comunidades negras.

Segundo Moscovici (2001), é através da linguagem que pensamos. Ea linguagem é a expressão das representações e da cultura. As representações estão presentes em todas as interações humanas. Pessoas e grupos criam representações ao longo do processo de comunicação que ocorre nas ruas, nos bares, nos escritórios, em qualquer ambiente em que as pessoas dialogam, comentam, julgam, emitem opiniões. Sendo criadas, as representações adquirem vida própria, circulam e ensejam o surgimento de novas representações. E passam a exercer influência decisiva sobre as relações sociais, sobre as escolhas e as ações das pessoas.

A finalidade das representações é proporcionar a familiarização, fazer com que os objetos, pessoas e acontecimentos sejam percebidos e compreendidos em relação a conhecimentos prévios. Para isso dois mecanismos são postos em funcionamento: a ancoragem e a objetivação. Ancorar consiste em classificar e dar nome a alguma coisa, isto é, incluir um objeto, pessoa ou acontecimento em uma determinada categoria, rotulando-o com um nome conhecido.

$\cap \quad$ Objetivar consiste em converter aquilo que é abstrato em algo quase concreto, transformar um conceito em imagem, traduzir o que está na mente em algo tangível (Moscovici, 2001).

As representações sociais são, portanto, "um conjunto coletivamente compartilhado de crenças, imagens, metáforas e símbolos num grupo, comunidade, sociedade ou cultura" (Wagner, 1998, p.3). São conhecimentos práticos, pois envolvem a prática interativa e orientam as ações no cotidiano. Conforme afirma Wagner (1998), as idéias criadas pelo pensamento individual têm como referência necessária o lastro mental constituído social e culturalmente.

Nesse sentido, em se tratando de representações sociais, as respostas individuais são consideradas como "manifestações de tendências do grupo de pertença ou de afiliação da qual os indivíduos participam" (Spink, 2003, p.120). É na esfera pública que a ação de sujeitos sociais desenvolve e mantém conhecimentos sobre a própria comunidade. Dessa forma, os sujeitos constroem uma identidade social, uma lógica de pertencimento, e dão sentido ao mundo (Jovchelovitch, 2003).

De acordo com Minayo (2003), há representações sociais que são mais abrangentes, que predominam no âmbito de uma sociedade. São representações que expressam uma visão de mundo em determinado momento histórico, que revelam as concepções das classes dominantes. Nessas representações estão presentes a dominação, a resistência, o conformismo, as contradições e os conflitos, numa conexão dialética com a realidade. Mas é importante assinalar que"cada grupo social faz da visão abrangente uma representação particular, de acordo com a sua posição no conjunto da sociedade" (p.110).

\section{Método}

\section{Participantes}

Participaram da pesquisa vinte moradores de Tijuaçu, de ambos os sexos, indicados pela Associação Quilombola local. Tijuaçu é um distrito distante $23 \mathrm{~km}$ da cidade do Senhor do Bonfim, sede do município. O município está situado ao norte da Bahia, distante cerca de $350 \mathrm{~km}$ de Salvador. O distrito de Tijuaçu é composto pela vila e vários povoados. Segundo Machado, Salgado, Kropidlowski e Santos (2005), o distrito tem aproximadamente 4.900 habitantes. Algo em torno de um terço da população vive na zona urbana (na vila). Sua economia é baseada no extrativismo (do ouricuri)e na venda de acarajé. Sua expressão cultural mais conhecida é o "samba de lata", folguedo em que um instrumento - a lata -, utilizado originariamente para o transporte de água, transforma-se em instrumento musical. O distrito de Tijuaçu foi reconhecido recentemente como remanescente de quilombo. 


\section{Instrumentos}

Uma Lista de Complementação de Frases, composta por onze frases incompletas, abordando os seguintes tópicos: 1) o lugar (Tijuaçu é um lugar ...);2) os moradores (Quem mora em Tijuaçu ...); 3) o suposto olhar dos outros (Quem não é de Tijuaçu pensa ...); 4) as mulheres (As mulheres de Tijuaçu ...); 5) os homens (Os homens de Tijuaçu ...); 6) os mais velhos (As pessoas mais velhas de Tijuaçu ...); 7) os jovens (Os jovens de Tijuaçu ...);8) as crianças (As crianças de Tijuaçu ...); 9) ser quilombola (Ser quilombola ...); 10) negritude (Acredito que ser negro ...); 11) o futuro (Para melhorar a vida dos quilombolas ...).

\section{Procedimentos}

A Lista de Complementação de Frases foi aplicada em sessão única, com todos os participantes, numa sala disponibilizada pela Associação Quilombola de Tijuaçu. Os participantes foram designados pela própria associação, a partir da orientação de que deveriam ter idade mínima de 12 anos e que deveriam apresentar competência relacionada à leitura e à escrita que Ihes permitisse responder a um questionário.

Os dados obtidos foram analisados por tópico indicado no instrumento de coleta. Dentre as expressões apresentadas por todos os participantes, foram identificadas e agrupadas aquelas que mantêm entre si evidente similaridade em termos de sentido, ou seja, aquelas expressões ou frases atravessadas por uma idéia ou sentido comum. Foram consideradas crescentemente significativas as representações cujo agrupamento foi constituído pelas expressões de dois ou mais participantes. Entretanto, as expressões não agrupadas foram consideradas significativas quando complementavam, especificavam ou esclareciam o sentido de um agrupamento. Adotou-se como orientação a noção de que cada discurso está relacionado com outros, pois que todo enunciado expresso por um determinado sujeito "é histórico e está historicamente condicionado" (Iñiguez, p.147).

\section{Resultados}

A amostra de participantes não foi homogênea. Foram vinte adolescentes e adultos, na faixa etária entre
12 e 41 anos, sendo quatro (20\%) do sexo masculino e 16 (80\%) do sexo feminino. Apenas o participante mais velho (41 anos) era casado. Os outros todos eram solteiros. Cinco participantes (25\%) cursavam o ensino fundamental e o restante (75\%) cursava ou já havia concluído o ensino médio (Tabela 1).

Na leitura dos resultados, procurou-se destacar as tendências gerais de respostas relacionadas a cada item da Lista de Complementação de Frases. A referência a cada participante é feita através do número indicador usado na Tabela 1. Nas transcrições das afirmações dos participantes, quando encontramos problemas ortográficos ou de concordância, optamos por efetuar adequações a uma escrita mais escorreita, cuidando para não comprometer o sentido da frase.

\section{O lugar}

O lugar é representado como maravilhoso e "bom de viver" por 50\% dos participantes. A grande maioria dos moradores é constituída por negros e, em

Tabela 1. Características dos participantes. Distrito de Tijuaçu, BA.

\begin{tabular}{|c|c|c|c|c|}
\hline $\begin{array}{l}\text { Partici- } \\
\text { pantes }\end{array}$ & Sexo & $\begin{array}{l}\text { Idade } \\
\text { (anos) }\end{array}$ & Escolaridade & Estado civil \\
\hline 1 & $\mathrm{~F}$ & 12 & Ensino Fundamental & Solteiro \\
\hline 2 & $\mathrm{~F}$ & 14 & Ensino Fundamental & Solteiro \\
\hline 3 & $\mathrm{~F}$ & 14 & Ensino Fundamental & Solteiro \\
\hline 4 & $\mathrm{~F}$ & 14 & Ensino Fundamental & Solteiro \\
\hline 5 & $\mathrm{~F}$ & 14 & Ensino Fundamental & Solteiro \\
\hline 6 & $\mathrm{~F}$ & 15 & Ensino Fundamental & Solteiro \\
\hline 7 & $\mathrm{~F}$ & 15 & Ensino Fundamental & Solteiro \\
\hline 8 & $\mathrm{~F}$ & 15 & Ensino Fundamental & Solteiro \\
\hline 9 & $\mathrm{~F}$ & 16 & Ensino Fundamental & Solteiro \\
\hline 10 & M & 16 & Ensino Fundamental & Solteiro \\
\hline 11 & $\mathrm{~F}$ & 17 & Ensino Fundamental & Solteiro \\
\hline 12 & $\mathrm{~F}$ & 17 & Ensino Fundamental & Solteiro \\
\hline 13 & $\mathrm{~F}$ & 18 & Ensino Fundamental & Solteiro \\
\hline 14 & $\mathrm{~F}$ & 20 & Ensino Fundamental & Solteiro \\
\hline 15 & M & 21 & Ensino Fundamental & Solteiro \\
\hline 16 & M & 22 & Ensino Fundamental & Solteiro \\
\hline 17 & $\mathrm{~F}$ & 23 & Ensino Fundamental & Solteiro \\
\hline 18 & $\mathrm{~F}$ & 25 & Ensino Fundamental & Solteiro \\
\hline 19 & $\mathrm{~F}$ & 27 & Ensino Fundamental & Solteiro \\
\hline 20 & M & 41 & Ensino Fundamental & Casado \\
\hline
\end{tabular}


função disso, as pessoas se percebem como iguais (25\%). "Tijuaçu é um lugar em que todos convivem juntos como uma família e todos são iguais" (Participante no.5). Há indicações referentes à cultura local: crenças, tradições, lendas, etc. (15\%). O lugar é percebido como tranqüilo, sem briga, sendo as pessoas unidas (20\%).

Parece haver um lastro histórico, constituído pela remanescência quilombola, a manter fortalecidas essas representações positivas. Mas há também indicações de aspectos negativos, de caráter histórico mais amplo: um participante afirma que a maioria das pessoas é analfabeta, outro que não há oportunidade de trabalho, e um terceiro afirma que ocorre discriminação por parte do branco. "Tijuaçu é um lugar muito bom de viver, só que temos um problema que é a discriminação do branco com o negro" (participante no.18).

\section{Os moradores}

São pessoas que se orgulham de ser negras e do lugar em que moram (15\%), um lugar identificado com a família (10\%). São mobilizadas pela herança quilombola (15\%) e lutam pelo desenvolvimento da comunidade (10\%). "Quem mora em Tijuaçu é muito privilegiado, pois somos uma comunidade unida pela força quilombola" (participante no.17).

\section{O suposto olhar dos outros}

Como os quilombolas se percebem diante do olhar dos outros? Encontramos aqui visões que se opõem, mas que parecem as duas faces de uma mesma moeda. A visão positiva considera que o povo gosta muito do lugar (15\%), e o lugar é tranqüilo (10\%), bom de viver (15\%), é até mesmo objeto de inveja dos outros (5\%). A visão negativa considera que é um lugar ruim, abandonado, que não vai para frente, habitado por negros ignorantes

. e sofredores (20\%)." Quem não é de Tijuaçu pensa que é

(um lugar) de negros ignorantes que não sabem quais ồ são seus direitos e deveres" (participante no.13)."Quem @ não é de Tijuaçu pensa que os mais velhos já nasceram 3 com a lata d'água na cabeça" (participante no.9).

\section{As mulheres}

As mulheres são representadas como bonitas e elegantes (30\%), legais (10\%), alegres e felizes (10\%), esforçadas e batalhadoras/trabalhadoras (100\%). São pessoas que ajudam seus maridos (10\%)."As mulheres de Tijuaçu são guerreiras, batalhadoras, que lutam dia e noite para uma descoberta nova, para uma vida melhor" (participante no.19).

\section{Os homens}

Os homens são representados como trabaIhadores (55\%), responsáveis (15\%), embora haja exceções, aqueles que se desviam do trabalho (15\%). Alguns trabalham fora (em outras localidades) (15\%) e outros na roça (25\%), no próprio distrito. São pessoas que acreditam no futuro (15\%). "Os homens de Tijuaçu alguns são trabalhadores e responsáveis, outros gostam de malandragem" (participante no.4). Os homens são representados ainda como lutadores e esforçados (15\%).

\section{Os mais velhos}

Os mais velhos são concebidos como sábios (10\%). "As pessoas mais velhas são mais sábias, sabem do tempo passado, como era a escravidão" (participante no.4). Conhecedores da história da comunidade (45\%), eles são respeitados na comunidade (10\%). "As pessoas mais velhas são muito educadas, são elas que ajudam a estudar a história da comunidade" (participante no.15). São experientes (15\%), passaram por dificuldades, contam histórias dos seus ancestrais. "As pessoas mais velhas de Tijuaçu são muito especiais na comunidade" (participante no.14).

\section{Os jovens}

Há uma dupla visão dos jovens. Há aqueles que gostam de curtir, que preferem as festas, que pouco se interessam pelas questões históricas do lugar, e que são considerados pouco responsáveis ou rebeldes (15\%). "Os jovens de Tijuaçu, nem todos participam do conhecimento do seu lugar" (participante no.7). E há aqueles que se interessam pela comunidade (10\%). Entretanto, de modo geral, os jovens são representados como inteligentes (20\%), estudiosos (15\%), preocupados com o futuro (10\%), mas carentes de oportunidades de trabalho e de profissionalização (15\%). .... a maioria com 17 anos sai para trabalhar fora, porque não tem emprego para eles" (participante no.2). 


\section{As crianças}

As crianças são vistas como pessoas alegres (25\%), que gostam de brincar (35\%). "As crianças de Tijuaçu são alegres, brincalhonas e divertidas" (participante no.6). Algumas participam dos movimentos da comunidade (15\%) e se interessam por "aprender sobre a raça" (participante no.11). Outras são consideradas "rebeldes", pouco "educadas" (10\%). As crianças são representadas, ainda, como possibilidades projetadas para o futuro (15\%).

\section{Ser quilombola}

Ser quilombola é pertencer a uma comunidade negra, assumir sua cor, sentir orgulho (50\%), lutar contra o racismo, pela liberdade, pelos ideais, pelos objetivos (20\%). "Ser quilombola é ter orgulho de sua comunidade e de seu povo" (participante no.12). Ser quilombola é ter a"consciência limpa"(10\%), isto é, sem preconceito. "Ser quilombola é pertencer a uma comunidade negra" (participante no.16).

\section{Negritude}

Ser negro não significa defeito, não é mais ser desprezado (15\%), "é ser como qualquer outra pessoa" (participante no.3)."Acredito que ser negro não é motivo para ter vergonha, mas para ter orgulho" (participante no.10). A afirmação do orgulho reaparece em 35\% das expressões dos participantes.

\section{O futuro}

O futuro aparece relacionado principalmente à necessidade de diminuir ou "acabar com o racismo" (25\%). Para isso é preciso que cada um faça a sua parte e todos se organizem (20\%). "Para melhorar a vida dos quilombolas é preciso que todos estudem e se organizem" (participante n.20). É preciso que todos se unam, participem, e "que o povo de Tijuaçu seja mais informado" (participante no.1). A importância da informação e do estudo é ressaltada (10\%). Além disso, indica-se a necessidade de que haja mais investimento governamental (15\%) e mais oportunidade de emprego (15\%).

\section{Discussão}

As representações sociais, expressas pelos participantes deste estudo, são bastante reveladoras quanto ao lugar e às pessoas em sua dinâmica social. E, embora proporcionem mais indicações e sugestões do que conclusões, essas representações permitem uma visão panorâmica da comunidade quilombola de Tijuaçu. Na verdade, são imagens e concepções que emergem num jogo dialético de contrários, conforme sugere Minayo (2003). Por exemplo, parece haver uma tensão entre o "lugar tranqüilo" (expressão de 20\% dos participantes) e a "luta" pelos objetivos, pelos ideais e, principalmente, contra o racismo (20\% no item nove e $25 \%$ no item 11). Como a comunidade se percebe unida, composta por iguais (25\%), a discriminação étnica é percebida lá fora (no outgroup), sendo os quilombolas percebidos como "negros ignorantes e sofredores" (na expressão de 20\%). Porém há indicações de que o preconceito ronda e adentra a comunidade, de tal forma que enseja a seguinte afirmação do participante no.2: "muitas (crianças) crescem com preconceito das outras porque são negras".

O quilombola enfrenta as condições adversas da vida assumindo uma dupla tarefa (individual e coletiva): garantir a sua sobrevivência (e de sua família) e fortalecer a comunidade na luta contra o preconceito e a discriminação. Nessa tarefa, mais do que "bonitas e elegantes" (30\%), as mulheres são representadas como "esforçadas, batalhadoras e trabalhadoras" (100\%). Os homens são também trabalhadores (55\%). Fortalecer a comunidade significa fortalecer, ao mesmo tempo, a própria identidade, ancorando-a em profundas raízes históricas. E é interessante notar que essa ancoragem apresenta fortes tonalidades afetivas, que vão da vergonha ao orgulho, por exemplo. Dos participantes, 15\% dizem que "ser negro não significa defeito, não é mais ser desprezado" e 35\% afirmam o orgulho de ser negro. Fortalecer a comunidade significa também proteger-se, elevar a auto-estima. Ocorre aqui um trânsito dialético entre o "eu" e o "nós".

Os quilombolas mais velhos são os difusores e mantenedores das representações mais antigas e estáveis, a partir das quais são ancorados os novos conhecimentos. Os mais velhos são conhecedores da história da comunidade, como indicam 45\% dos participantes. Essa difusão se dá basicamente pela tradição oral. Porém a tradição oral aqui não remete à 
ingenuidade infantil, como ocorria na concepção da década de 1920, conforme Gouvêa (2005), mas, sim, a um compromisso histórico comunitário para com a resistência quilombola.

Nota-se que há um movimento de resistência às representações mais abrangentes (baseadas no preconceito étnico), que são expressões da dominação, e isso está de acordo com as indicações de Minayo (2003). Nitidamente são enfatizadas as idéias de beleza, alegria, otimismo, inteligência, capacidade e gosto pelo trabalho. Essa ênfase sugere um movimento histórico que vai de ser desprezado a ser valorizado, de ser ignorante a ser bem informado, de ser feio a ser bonito, de ser incapaz a ser capaz, de ter vergonha a ter orgulho. Nesse sentido, são expressivas as afirmações do participante no.1 ("Os negros de Tijuaçu são famosos no Brasil") e do participante no.17 ("Quem não é de Tijuaçu pensa que somos esquecidos de tudo e de todos, mas se engana quem pensa assim, pois somos muito bem reconhecidos nacionalmente pelo Governo Federal"). Para compreender melhor tais afirmações, convém assinalar que Tijuaçu foi reconhecido legalmente como remanescente de quilombo e que tem sido alvo, nos últimos anos, de várias reportagens para a televisão e de vários estudos acadêmicos.

Portanto em vez da idéia do embranquecimento, já presente no Brasil na década de 1930, segundo assinala Gouvêa (2005), na comunidade quilombola de Tijuaçu ocorre a assunção da cor, da raça, da negritude. Esse processo de particularização (Minayo, 2003) provavelmente esteja também envolvido no fortalecimento do sentimento de pertença e da autoafirmação, e na elevação e manutenção da auto-estima.

Nesse sentido, há a representação de que o quilombola deve comprometer-se com a causa comunitária. Isto inclui "assumir sua cor, sentir orgulho" (50\%), "diminuir ou acabar com o racismo" (25\%), cada

๑ um fazer sua parte e todos se organizarem (20\%). E esse

in compromisso deve começar desde muito cedo, desde 亩 quando criança, desenvolvendo o interesse em « "aprender sobre a raça", participando dos "movimentos" 3 da comunidade (15\%).

Se tomamos como referência o estudo realizado por Cavalleiro (2003), compreendemos que, em relação ao processo de socialização, algo de outra ordem acontece entre os quilombolas de Tijuaçu. Em vez do medo e do silêncio na educação dos filhos, eles imprimem um processo de educação indutor da conscientização, da assunção da negritude, do pertencimento à comunidade quilombola e da luta contra o preconceito e a discriminação. Lutar contra o racismo significa manter viva a chama da luta pela liberdade. Trata-se de uma postura de enfrentamento francamente assertiva.

Este estudo tem caráter exploratório e certamente apresenta muitas limitações em termos de abrangência e de profundidade. Uma delas é a quantidade reduzida de participantes, assim como a não inclusão de analfabetos, em função do instrumento utilizado, dado que os próprios participantes apontaram para os altos índices de analfabetismo na comunidade. Outras limitações podem ser atribuídas à faixa etária dos participantes, que incluiu apenas um com mais de trinta anos, e ao fato de os participantes não poderem optar pelos temas a serem focalizados, pois que esses foram definidos previamente. Além disso, os participantes foram indicados pela associação quilombola local, o que pode ter contribuído para aumentar o índice de similaridades nos discursos. Entretanto, por ser um estudo exploratório, uma abordagem mais superficial ao fenômeno foi condição limitante, mas, também, uma parcimônia necessária. Outros aspectos da dinâmica sociocultural da comunidade quilombola são de suma importância para uma compreensão cada vez mais adequada das populações negras. Dentre esses aspectos podemos destacar a escolarização, as práticas relacionadas à saúde, a organização do trabalho, as crenças, as artes e a religiosidade. Esses aspectos poderão ser objetos de investigações futuras.

Ainda assim, este estudo pode provocar reflexões bastante atuais sobre o preconceito étnico e o tratamento dado aos diferentes no Brasil. Figueroa (2004), ao abordar o conceito de eqüidade, esclarece que se trata de um "aprofundamento do princípio de igualdade formal de todos diante da lei" (p.16). O conceito de eqüidade comporta a compreensão de que indivíduos e coletivos especiais ou diferentes devem ser tratados de modo especial ou diferente. A autora acrescenta que "no Brasil, país multiétnico e multicultural, que reconhece essa diversidade na sua própria Carta Constitucional, a igualdade de direito não pode representar a homogeneização de tratamento de indivíduos e de povos" (p.16). Nessa linha de raciocínio, e pensando em políticas públicas, o tratamento 
eqüitativo supõe que haja séria preocupação quanto à adequação das ações e programas governamentais às especificidades de cada coletivo.

Freqüentemente os estudos que dão suporte aos programas governamentais visam indicar amplas possibilidades de generalização. E não poderiam deixar de ser assim, dada a dimensão dos propósitos em termos de políticas públicas. Entretanto a sugestão que emerge do presente estudo é justamente a de que essa necessidade de generalização, por si só, pode ser insuficiente. Precisa caminhar par a par com a necessidade de conhecer as especificidades, principalmente quando estão em pauta as denominadas ações afirmativas. Do contrário, impõe-se o risco de perder logo aquilo que se busca: a eqüidade, o tratamento diferente aos diferentes.

Afinal, ao buscar prioritariamente a generalização, parte-se implicitamente do pressuposto de que a população negra é homogênea. Perde-se, portanto, a perspectiva da diversidade na diversidade. Em função dessa possível diversidade no âmbito da população negra, é necessário considerar que as crenças e conhecimentos compartilhados pelos membros de cada comunidade quilombola, por exemplo, poderão atuar de modo favorável ou desfavorável, em dado momento histórico, à efetivação das ações implementadas a partir de políticas públicas; mesmo quando essas ações resultarem de demandas da própria comunidade.

Em síntese, importa saber se as intervenções institucionais são passíveis, em sua forma e significados, de obter a conexão necessária com as práticas e saberes pré-existentes naquela comunidade específica. Nesse ponto da longa história de preconceitos que se avolumam, hoje, cada vez mais sutilmente, sobre a população negra na cultura brasileira, parece pertinente conhecer o que cada comunidade quilombola tem feito para resistir e manter sua identidade, o que tem feito das representações mais abrangentes das classes dominantes sobre as comunidades negras.

\section{Referências}

Camino, L., Silva, P., \& Machado, A. (2004). As novas formas de expressão do preconceito racial no Brasil: estudos exploratórios. In M. E. O. Lima \& M. E. Pereira (Orgs.), Estereótipos, preconceitos e discriminação: perspectivas teóricas e metodológicas (pp.119-137). Salvador: EDUFBA.
Cavalleiro, E. S. (2003). Veredas das noites sem fim: um estudo com famílias negras de baixa renda sobre o processo de socialização e a construção do pertencimento racial. Tese de doutorado não-publicada, Universidade de São Paulo.

Duckitt, J. (1992). Psychology and prejudice: a historical analysis and integrative framework. American Psychologist, 67 (10), 182-193.

Figueroa, A. L. G. (2004). Contextualização conceitual e histórica. In Seminário Nacional Saúde da População Negra. Brasília: Ministério da Saúde/Secretaria Especial de Políticas de Promoção da Igualdade Racial.

Fiske, S. T. (1998). Stereotyping, prejudice, and discrimination. In D. Gilbert, S.T. Fiske \& G. Lindzey. The handbook of social psychology (pp.357-411). Boston: McGraw-Hill.

Gouvêa, M. C. S. (2005). Imagens do negro na literatura infantil brasileira: análise historiográfica. Educação e Pesquisa, 31 (1), 79-91.

Iñiguez, L. (2004). Prática de análise do discurso. In L. Iñiguez (Org.), Manual de análise do discurso em Ciências Sociais. Petrópolis: Vozes.

Jovchelovitch, S. (2003). Vivendo a vida com os outros: intersubjetividade, espaço público e representações sociais. In P.A. Guareschi \& S. Jovchelovitch (Orgs.), Textos em representações sociais (8a. ed. pp.63-85). Petrópolis: Vozes.

Machado, P. B., Salgado, J. S., Kropidlowski, M., \& Santos, V. (2005). Tijuaçu:uma resistência negra no semi-árido baiano. Senhor do Bonfim: Prefeitura Municipal de Senhor do Bonfim.

Minayo, M. C. S. (2003). O conceito de representações sociais dentro da sociologia clássica. In P. A. Guareschi \& S. Jovchelovitch (Orgs.), Textos em representações sociais (8a. ed., pp.89-111). Petrópolis: Vozes.

Moscovici, S. (2001). Representações sociais: investigações em psicologia social. Petrópolis: Vozes.

Paré, M. L. (2000). Auto-imagem e auto-estima na criança negra: um olhar sobre o desempenho escolar. Dissertação de mestrado não-publicada, Pontifícia Universidade Católica do Rio Grande do Sul, Porto Alegre.

Spink, M. J. (2003). Desvendando as teorias implícitas: uma metodologia de análise das representações sociais. In P. A. Guareschi \& S. Jovchelovitch (Orgs.), Textos em representações sociais (8a. ed. pp.117-145). Petrópolis: Vozes.

Stangor, C. (2000). Volume overview. In C. Stangor (Ed.), Stereotypes and prejudice: essencial readings (pp.1-16). Philadelphia: Psychology Press.

Wagner, W. (1998). Sócio-gênese e características das representações sociais. In A. S. P. Moreira \& D. C. Oliveira (Orgs.), Estudos interdisciplinares de representação social (pp. 3-25). Goiânia: AB.

Recebido em: 3/5/2006

Versão final reapresentada em: 19/9/2006

Aprovado em: 9/10/2006 
